\title{
TRAUMATIC KNEE INJURY PATTERNS IN ANATOLIAN FOLK DANCERS: A CASE SERIES AND LITERATURE REVIEW
}

\author{
${ }^{1}$ Istanbul Bilim University, Istanbul, Turkey \\ Faculty of Medicine, Department of Orthopedics and Traumatology \\ ${ }^{2}$ Sisli Florence Nightingale Hospital, Istanbul, Turkey \\ Department of Physical Therapy and Rehabilitation Department \\ ${ }^{3}$ Bahcesehir University, Istanbul, Turkey \\ Medical Faculty, Orthopedics and Traumatology Department
}

NESLIHAN AKSU ${ }^{1}$, BUSRA AKGONUL ${ }^{2}$, TANER AKSU ${ }^{3}$, VEFA ATANSAY ${ }^{1}$, and AYHAN NEDIM KARA ${ }^{1}$

\begin{abstract}
Lower extremities, especially the knee region, are susceptible to traumatic injuries because of long-lasting hard landings and impacts. Most of the injuries described in the literature are associated with ballet. In this review study, the authors tried to present the traumatic knee injury patterns of the Anatolian folk dance. The Fire of Anatolia dance group consists of 82 dancers (37 males [45.1\%] and 45 females [54.9\%]) with the mean age of 27.96 (SD = 5.05) years (range: 18-38 years). The major folk dances of the region are Zeybek, Halay, Horon, Teke, Roman, Karsilama, Bar and Lezginka ("the Caucasian"). The dancers suffered from 9 orthopedic injuries requiring surgical treatment (3 meniscus tears, 4 anterior cruciate ligament tears, 1 posterior cruciate ligament tear, 1 patellar dislocation) during a 10-year period. The authors investigated solely the traumatic injuries of these folk dance styles and aimed at revealing the traumatic knee injury patterns in this case series and literature review. On the one hand, the Anatolian folk dancers experienced meniscus tears following frequent squats and twists on single leg stances, typical of Horon and Zeybek. On the other hand, anterior cruciate tears happened after jumps and landings in the Caucasian (Lezginka jump) dance. A posterior cruciate ligament tear was also seen after the Caucasian dance landing. The split figure in the Karsilama dance ended up with patellar dislocation. Certain dance figures seem to be related to specific types of injuries. Int J Occup Med Environ Health. 2019;32(5):585-93
\end{abstract}

Key words:

dance injury, patellar dislocation, meniscus tear, knee injury, anterior cruciate ligament injury, posterior cruciate ligament injury

\section{INTRODUCTION}

Most of the injuries described in the literature are associated with ballet $[1-8]$. In the present study, the foot and ankle was the most common site (40\%), which falls within the range reported in previous studies (15-66\%) [1]. In the present study, the knee was the third most commonly injured location (16\%), falling within the range reported in previous studies (7-29\%) [1-6]. Knee problems account for $14-20 \%$ of all complaints and $>50 \%$ of them are retropatellar (synovial plica, medial chondromalacia, lateral patellar facet syndrome, patellar subluxation, fat pad syndrome) in ballet dancers [7]. Knee injuries in ballet dancers have been reported in the literature with the following prevalence: peripatellar knee pain (51-57\%), ligamentous

This article's abstract was presented for an oral presentation at the APOA (20th Asia Pacific Orthopaedic Associations) 2018 Conference.

Received: October 28, 2018. Accepted: July 10, 2019.

Corresponding author: Neslihan Aksu, Istanbul Bilim University, Faculty of Medicine, Department of Orthopaedics and Traumatology, Abide i Hurriyet Cad No 164 Sisli 34381 Istanbul, Turkey (e-mail: neslihan.aksu@gmail.com). 
sprain (10-24\%), patellar tendinitis (8-15\%), iliotibial band syndrome (4-11\%), pes anserine tendinitis $(2-5 \%)$, popliteal cyst ( $0-2 \%)$, and torn meniscus (1-2\%) [7]. The prevalence of injuries sustained by professional dancers belonging to a major Spanish ballet company practicing classical, neoclassical, contemporary, and Spanish dance were acute traumatic in $24.7 \%$, and nontraumatic overuse in $75.3 \%$ of the cases [8]. This study showed that $18 \%$ of the 366 injuries were in the knee region which included patellofemoral syndrome (8.2\%), patellar tendinitis $(6.8 \%)$, chondral lesions (3\%), and quadriceps muscle injury $(1.1 \%)$ [8].

The literature is scarce, with only 2 articles concerning traumatic knee injuries leading to surgery in this group of patients. One of them was written by Mauffels [9] and included 4 professional ballet dancers who had their anterior cruciate ligament reconstructed, and the other was drawn up by Aksu [10] and provided descriptions of knee injuries in 7 professional folk dancers (2 anterior cruciate ligament injuries, 1 posterior cruciate ligament reconstruction, 3 meniscus repair cases, and 1 medial patellofemoral ligament repair). In this case series and literature review study, the authors tried to present the traumatic knee injury patterns typical of the Anatolian folk dance.

\section{METHODS}

The Fire of Anatolia dance group consists of 82 dancers (37 males [45.1\%] and 45 females [54.9\%]) with a mean age of 27.96 ( $\mathrm{SD}=5.05)$ years (range: $18-38$ years). The dancers suffered from 9 orthopedic injuries requiring surgical treatment (3 meniscus tears, 4 anterior cruciate ligament tears, 1 of which involved a posterolateral corner tear, 1 posterior cruciate ligament tear, and 1 patellar dislocation) during a 10 -year period. The authors investigated solely the traumatic injuries of these folk dance styles and aimed at revealing traumatic knee injury patterns. They had previously obtained informed consents of all the subjects involved in this study.

\section{Anatolian folk dances}

The major folk dances in the Anatolian region are Zeybek, Halay, Horon, Teke, Roman, Karsilama, Bar and the Lezginka ("the Caucasian") [10-14]. The Fire of Anatolia dance group is a leading professional dance group of the region, which performs dances of various ethnic groups which have dwelt in Anatolia for centuries and still live together. The names of the folk dances in this region, based on their region of origin, are as follows: Zeybek (Aegean and Western Anatolia), Halay (Central and Southern Anatolia), Horon (Eastern Black Sea), Teke (Southern Anatolia), Roman and Karsilama (Thracian), Bar (Northern Anatolia), and Lezginka (Eastern Anatolia) [10-14]. While the boundaries of the dances can be defined as above, it is hard to establish a definite boundary for the Anatolian folk dances. The music has a 6/8 rhythm, the melody is clear and dynamic, and the pace is fast [11]. Halay is the most widely known and performed type of the Anatolian folk dances. During the dance, male and female dancers are lined up in turns to form a straight line while holding each other by the hand. The dance starts with slow steps and gradually speeds up. The steps of the Halay dance are usually based on foot figures [11-14]. The final dance in this dance group is Garzane Halay, taking its name from the Garzane region of the Bitlis Province in Eastern Anatolia [12]. There are consistent shoulder shakes, hard foot figures and soft head movements in the Garzane Halay. In the finale, the dancers hold each other by the hand and jump together; this is called the Garzane jump. The moves in the Bitlis Halay are rich in terms of choreography. There are several forms of line-ups. The dancing couples jump and clap while standing next to each other [12].

Horon is a lively folk dance of the Black Sea region of Anatolia, performed to kamancheh and drum music. The physical features of Horon dancers are anthropometrically more defined than those of Halay dancers, thanks to the high tempo of the music [12-14]. Their body fat percentages and circumferences are lower than those of the Halay 
dancers $[12,14]$. Dancers in this group can reach a pace of 218 steps/min during performance as was recorded by a step counter [11].

Zeybek is a folk dance of the Aegean region. The dance may be performed solo or by a circle of singles. When performed by a group, dancers dance Zeybek without holding each other [12,14].

Bar is one of the folk dances of the Northeastern Anatolia. Dancers form lines to perform these esthetic dances of nobility and bravery. The dances depict tales of victories of war, valor and heroism [12,14].

Teke is a folk dance performed by Turkmens in Southern Anatolia. It has 3 main sections: wobbling, hopping on 1 foot, and running away like a cantering horse [14].

Lezginka, also called "the Caucasian" in the Caucasus region, is a solo pair dance. The dance is a half-solo halfgroup performance in which young people can show their skills individually. In some jumps, the dancer lands on his knees, jumps up and lands on his knees again $[10,11]$. The energetic and hard jumps with aerial sideway spins are the main moves of the Lezginka dance. The Lezginka moves of leaping and tiptoeing are harder and faster than the pointe figures of ballet.

\section{RESULTS}

On the one hand, the Anatolian folk dancers involved in the study experienced meniscus tears following frequent squats and twists on single leg stances in the Horon and Zeybek dances. On the other hand, anterior cruciate ligament (ACL) tears happened after jumps and landings in the Caucasian (Lezginka jump) dance. A posterior cruciate ligament (PCL) tear was also seen after the Caucasian dance landing. The split figure in Karsilama ended up with patellar dislocation.

\section{Meniscal tears}

Meniscal tears in dancers may range from partial thickness wear or tear to total avulsion of the meniscus in the joint. Meniscal injuries typically occur following the entrapment of the meniscus between the femoral condyle and the tibial plateau during a turn on a flexed knee. A forceful flexion causes pain in the posterior horn rupture; similarly, a forceful extension causes pain in the anterior horn rupture. Meniscal tears result from percussive squats or from "screwing the knee" to increase turnout in ballet trainees [15].

In folk dances, meniscal tears occur due to forceful squatting and standing, or turning on a fixed foot. Folk dances are characterized by much faster and harder knee movements than ballet. The Halay and Horon dances have fast and pounding feet moves [12,13]. Horon has been shown to be the fastest dance in the world, with $218 \mathrm{steps} / \mathrm{min}$ [9]. Unlike ballet dancers, folk dancers do not tiptoe or perform movements that force the lower extremity to excessive external rotation. Of all the Anatolian folk dances, the Roman dance has particularly frequent moves with external rotation of the hip [12]. Dancers who cannot adequately perform the external rotation try to compensate it by turning their knees, which in turn poses a risk for meniscal tears. Standing on 1 foot for a long time and performing turns are the basic figures of the Zeybek dance.

During the dance, the groups of singles line up to form a circle [10]. During the performance of these moves, if the dancer cannot turn his/her torso on his/her foot, he/she forces the knee to execute the turn. Such a movement may also result in meniscal tears. Modern dancers perform the squat move as they carry their partner. This move might cause excessive load on the menisci and their entrapment further. With unfitting shoes or unsuitable floors, the shoe grip of the floor may cause a forceful turn of the knee, resulting in an injury.

In abnormal alignment of the lower extremity, a poor technique and unbalanced flexibility will cause excessive rotation of the knee, which in turn may lead to meniscal tears and ligament sprains. The "swayback" knees (hyperextension of the knee due to excessive ligamentous laxity), 
particularly in ballet dancers, are usually associated with weak leg muscles making the dancer more susceptible to knee injuries [15].

Although meniscal tears are common, lateral meniscus damages are more often encountered in dancing when compared to other sports. These tears are rarely acute and result from small recursive traumas in the knee. The "overturning" movement of the knee (seen mostly in dancers), combined with the strained iliotibial band, is thought to cause a degenerative tear by entrapping the lateral meniscus [15].

Three of the dancers who experienced meniscal tears had to undergo arthroscopic meniscus repair [10]. All the 3 dancers with meniscal tears were males; 2 were folk dancers and 1 was a modern ballet dancer. One of the folk dancers stated that he had got a feeling of a locked knee while squatting and standing during the Horon dance, and could unlock it by extending his legs and shaking them off. Another folk dancer stated that he had felt sudden pain while turning his body on a single leg. The modern ballet dancer claimed that he had experienced sudden pain during the squat move while carrying his partner, and the pain prevented him from doing further squat moves [10].

\section{Anterior cruciate ligament injuries}

Lezginka ("the Caucasian") is a solo pair dance. This dance resembles the macho characteristics of men from Kars, the furthest eastern province in Anatolia, and is performed solo or in groups of young people at weddings. Men's respect towards women, their pride and austerity with their partner can easily be seen during the dance. When dancing with his peers, the male dancer exhibits agile, belligerent, brave and yet aesthetic moves. The dance is a half-solo half-group performance in which young people can show their skills individually. The male dancers lift their arms sideways, much like the wings of an eagle [12]. The energetic and hard jumps with aerial sideway spins are the main moves of the Lezginka dance (Figure 1).

Eighty percent of the ACL injuries are noncontact injuries which occur due to a faulty landing after leaping. The risk of an ACL injury in dancers is significantly lower than among those who play team sports. Those injuries in team sports have a prevalence of $1-8 \%$ whereas the prevalence in modern ballet is $0.4 \%$ (in 5 years) [16]. In another study, the prevalence of ACL injuries in ballet dancers during a 10-year period was reported at 7\% [9]. The reason for the significantly lower prevalence of ACL injuries in dancers is the performance of the moves based on choreography (planned moves), training and experience. Sudden decelerations and turns, or the probability of contact injuries in dancing, are much lower than in competition sports. When compared to athletes, dancers learn the highly specific leaping and landing techniques at a much earlier age to acquire an aesthetic appearance [5,16-22].

Literature descriptions of dancer injuries which necessitate surgical treatment mostly come from the studies on ballet groups $[5,9,23]$. Both gender and dance type have an impact on ACL injuries. Unlike ballet dancers, modern dancers may improvise during the dance and this may increase the risk for ACL injuries. Female modern dance performers are under a greater risk of sustaining ACL injuries when compared to their male counterparts and all classical ballet dancers [5].

In this series, 4 dancers had ACL injuries, all of which had occurred during the landing sequence after leaping. For a secure landing, the knee ought to be in a flexion and varus position; landing while the knee is in an extension and valgus position is a risk factor for an ACL injury [9,16,24-26].

Four of the dancers had ACL tears; all of them were Caucasian dancers. One of the folk dancers said that, when performing a solo figure, he had heard a loud snapping sound at landing after rotating the knee out- 
ward while in excessive hyperextension. The dancer also reported excessive hypertension (recurvatum) and inward angulation (varus) of the knee with sudden swelling. The other folk dancer with an ACL injury reported that his knee had twisted at landing after leaping, which also caused swelling. The Caucasian dance performer with an ACL injury also stated that his knee had twisted with outward angulation at landing and swollen. In Caucasian dance jumps, both knees of the dancer are in flexion while he is in the air. One of the hips is abducted, flexed and rotated outward while the other is in maximum extension. Subsequently, the dancer extends both his knees and does the landing [10]. This move displaces the dancer sidewards on the frontal plane. The legs are open and both knees are in extension at landing. This frontal force forces one of the knees to the varus and the other to the valgus position at landing. Thus, the forceful external rotation in this valgus position may tear the ACL [27]. In many sports, including basketball and volleyball, players move in a sagittal direction during the jump and then land.

The 4 dancers with ACL injuries underwent arthroscopic reconstruction, and they were all male. This might be explained by the fact that male dancers do more jumping and landing than female dancers, which is in accordance with the choreography.

It is important to remember some of the special occasions of ACL injuries in dancers. Aerobics dancers may use knee braces whereas ballet and modern style dancers cannot use these as they impair the aesthetic appearance and stability. The outfits of professional dancers will not allow the use of such apparatus as well. In fact, there is no study in the literature confirming the preventive effect of knee braces when it comes to ACL injuries.

Those injuries can end the career of a professional dancer. Therefore, the dancer should pay utmost attention in landing during which ACL injuries are most likely to occur. A decent landing, good proprioception and strong

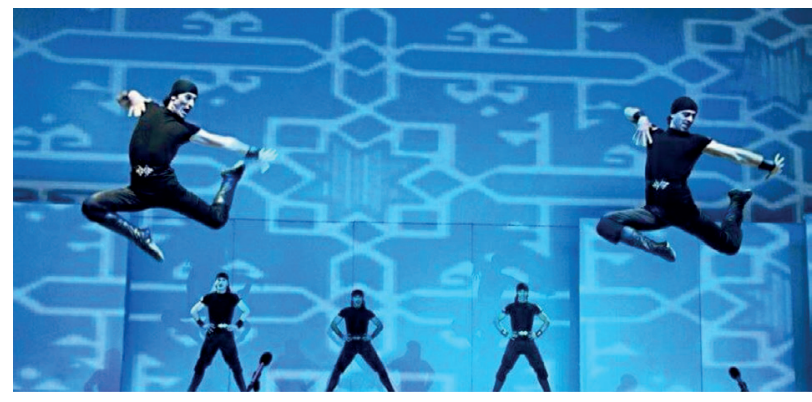

Figure 1. Energetic and hard jumps with aerial sideway spins in the Lezginka dance

muscles are all achievable with the application of the correct technique. The distance between the 2 knees should be more than the distance between the 2 feet during landing. Landing in the varus position with a flexed hip and knee will decrease the risk of ACL injury.

\section{Posterior cruciate ligament injuries}

These injuries are less common in dance and found more often in contact sports, as a result of direct trauma to the flexed knee, landing on the flexed knee with plantar flexion of the ankle, or hyperextension of the knee [15].

One Caucasian dance performer in the surveyed group underwent arthroscopic PCL reconstruction with hamstring autografting due to a PCL tear. In most of the Caucasian dance moves, the dancer quickly and recursively lands on his patella with the knee flexed. If the dancer falls on the tibia with his knee flexed, the tibia is pushed towards the posterior of the femur and forces the PCL to tear [10]. In the Caucasian dance moves, the dancer jumps on his flexed knee, and quickly and recursively turns his body. The PCL tear in the Caucasian dance performer involved in the study had occurred in such movement. Due to landing on their patella, all Caucasian dance performers use knee braces. If the dancer falls on his flexed knee with a wrong technique, the PCL might be torn [10]. The moves of leaping and tiptoeing are harder and faster than the pointe figures in ballet. In some jumps, the dancer lands on his knees, jumps up and lands on his knees again (Figure 2). 


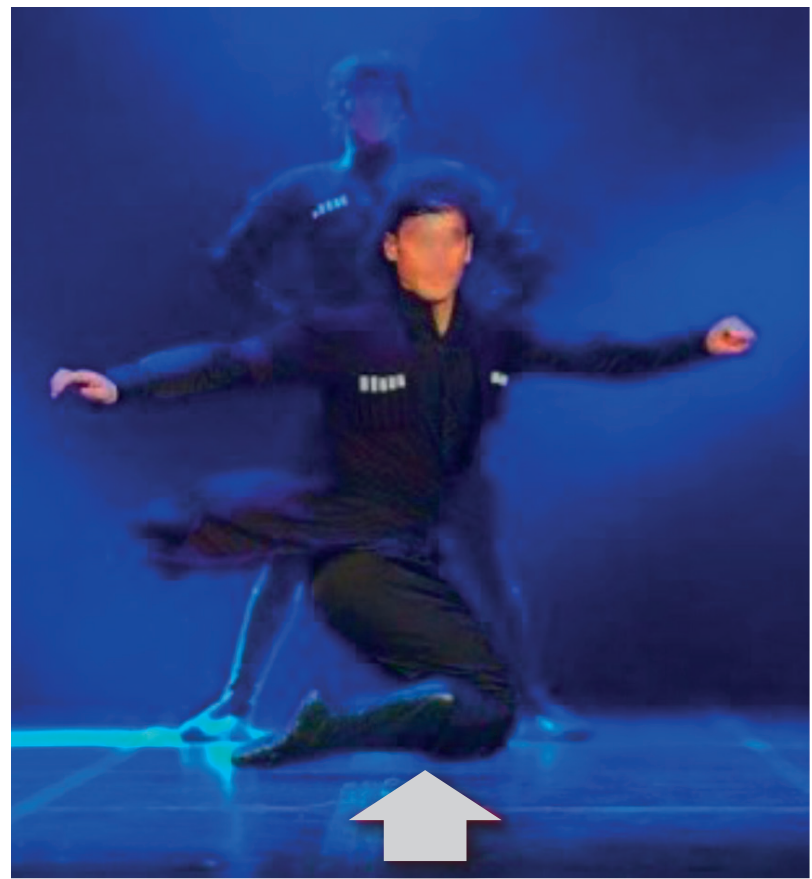

The arrow shows the dancer falling on the tibia with his knee flexed; the tibia is pushed toward the posterior of the femur and forces the PCL to tear.

Figure 2. The dancer landing on his knees in the Lezginka dance

Figure 2 shows the Lezginka jump on the knee. This figure, which involves jumping and landing on the shielded patella with pads and braces on a flexed knee, may pose a risk of a posterior cruciate ligament tear if the dancer lands on the proximal tibia instead.

\section{Patellar dislocation}

Patellar dislocation occurs after twisting the knee due to the valgus stress when the foot is on the ground, right before initiating a turn or jump in the air. The required torque is attained by stepping the "standing" foot on the ground; the leg is rotated according to both the foot and the thigh, and then it is angulated. The rotation and angulation of the leg in respect to the foot and the hip is increased. Several predisposing factors, including femoral trochlear dysplasia, patella alta, and lateralization of the tibial tuberosity, contribute to patellar instability and lat-

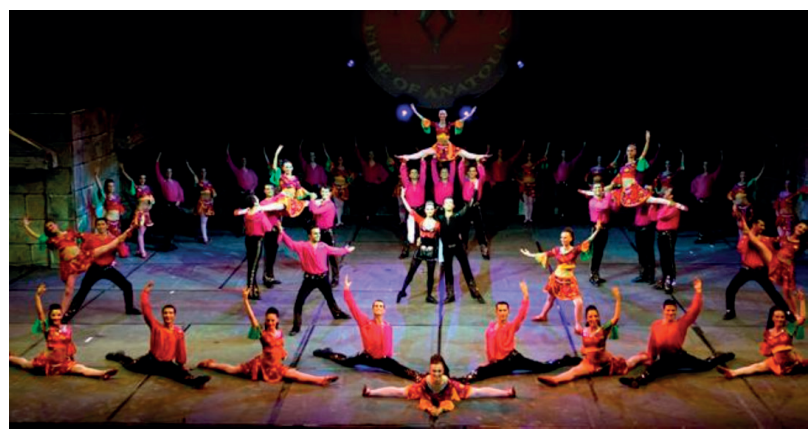

Figure 3. The split figure in the Karsilama dance

eral patellar dislocation [28]. Environmental factors and unfitting shoes may also cause the gripping of the shoe by the ground, thus leading to knee twisting and dislocation in turning dance moves [10].

Knee dislocation may develop without tearing of the medial retinaculum in dancers who have ligamentous laxity. These dancers report the "protruding" feeling in their knees; however, there is little or no swelling or tenderness. In addition, hemarthrosis and injuries are observed in most dancers with patellar dislocation. The medial retinacular tenderness or the retinacular defect can be palpated in the injured knee. In this series, 1 female dancer developed patellar dislocation. The dancer described a twist of her knee due to a shoe-grip at the beginning of her split move during the Karsilama dance, followed by a severe pain. At her presentation, the patella was dislocated. Reduction was performed under general anesthesia and the repair of the medial patellofemoral ligament was performed subsequently. The split figure may lead to patellar dislocation in people without any prior patellofemoral problems [10] (Figure 3).

Knee ligament and meniscus injuries in dancers can be prevented with rehabilitation programs. The main aim of these programs is to "stabilize" the soft tissues of the lower extremity, to correct postural and figural deformities, and to improve the motor control, posture and balance. The competitive dancers have well developed abductor muscles and tensor fasciae latae, but their adductor muscles 
and medial quadriceps may be weak. Strengthening the vastus medialis and adductor muscles, while flexing the lateral leg muscles, will help balance the muscles which are the dynamic and secondary stabilizers of the knee. Muscle balance will distribute the forces exerted on the lower extremity along the knee and thus cause less tension in the medial knee. In addition, it may reduce the risk of traumatic meniscus and ligament injuries.

The correct form should be emphasized. The "turnout" move should be executed from the hip, not from the knee or the ankle. In case this is not possible by increasing the ability to move the hip, a "turnout" move with a smaller angle should be recognized. Neuromuscular training and proprioception should not be overlooked in the rehabilitation and prevention process [15].

It has been shown that the ratio of ACL injuries in female athletes without plyometrics training is 0.43 whereas it has dropped to 0.12 in the trained ones. The training included instructions regarding proper jumping and landing techniques in the first stage, strength and agility in the second stage, and emphasis on the maximal jumping distance in the third stage [29]. Neuromuscular training reduces the rate of injury by teaching the athlete to perform the correct landing position and by increasing the dynamic stability of the knee.

\section{CONCLUSIONS}

Dancer injuries may result from insufficient muscle strength, an incorrect technique, some anatomical changes in the body, or inadequate motor development. Therefore, rehabilitation programs which provide muscle strength control, postural balance, proprioception and correct technical training will be much valued in preventing such injuries.

Certain dance figures seem to be related to specific types of injuries. It is known that neuromuscular exercise programs are applied to prevent knee injuries in professional athletes [30-33]. Likewise, it is important to inform the dancers who perform dances with a high risk of injuries and apply neuromuscular exercise programs to prevent knee injuries.

\section{REFERENCES}

1. Shah S, Weiss DS, Burchette RJ. Injuries in professional modern dancers: incidence, risk factors, and management. J Dance Med Sci. 2012;16(1):17-25.

2. Costa MS, Ferreira AS, Orsini M, Silva EB, Felicio LR. Characteristics and prevalence of musculoskeletal injury in professional and non-professional ballet dancers. Braz J Phys Ther. 2016;20(2):166-75, https://doi.org/10.1590/bjpt-rbf.2014.0142.

3. Ekegren CL, Quested R, Brodrick A. Injuries in pre-professional ballet dancers: Incidence, characteristics and consequences. J Sci Med Sport. 2014;17(3):271-5, https://doi. org/10.1016/j.jsams.2013.07.013.

4. Wanke EM, Koch F, Leslie-Spinks J, Groneberg DA. Traumatic injuries in professional dance-past and present: ballet injuries in Berlin, 1994/95 and 2011/12. Med Probl Perform Art. 2014;29(3):168-73, https://doi.org/10.21091/mppa.2014.3034.

5. Byhring S, Bo K. Musculoskeletal injuries in the Norwegian National Ballet: a prospective cohort study. Scand J Med Sci Sports. 2002;12:365-70, https://doi.org/10.1034/j.16000838.2002.01262.x.

6. Vassallo AJ, Hiller C, Stamatakis E, Pappas E. Epidemiology of dance-related injuries presenting to emergency departments in the United States, 2000-2013. Med Probl Perform Art. 2017;32(3):170-5, https://doi.org/10.21091/mppa.2017.3028.

7. Reid DC. Prevention of hip and knee injuries in ballet dancers. Sports Med. 1988;6(5):295-307, https://doi.org/10.2165/ 00007256-198806050-00005.

8. Sobrino FJ, Guillén P. Overuse injuries in professional ballet: influence of age and years of professional practise. Orthop J Sports Med. 2017;5(6):2325967117712704, https://doi. org/10.1177/2325967117712704.

9. Meuffels DE, Verhaar JA. Anterior cruciate ligament injury in professional dancers. Acta Orthop. 2008;79(4):515-8, https://doi.org/10.1080/17453670710015517. 
10. Aksu N, Atansay V, Aksu T, Koçulu S, Kara ŞD, Karalök I. Injuries requiring surgery in folk dancers: a retrospective cohort study of 9 years. J Sports Sci. 2018;6:108-17, https://doi. org/10.17265/2332-7839/2018.02.006.

11. Aksu N, Atansay V, Aksu T, Damla Kara Ş, Koçulu S, Karalök I. Overuse injuries in professional anatolian folk dancers: a descriptive study verified with MRI. Med Probl Perform Art. 2017;32(3):152-8, https://doi.org/10.21091/ mppa.2017.3025.

12. Gulbeyaz K. Classification of Turkish folk dances in terms of movement. IIB Inter Ref Acad Soc Sci J. 2013;4(11):69-78.

13. Karacabey K, Durgun R, Sönmez E, Adiloğulları İ, Özmerdivenli R. Determining and comparing the anthropometric measurements of the folk dancers of Anatolian folk dance and Horon regions. East Anatolis Res. 2008;6(3):56-61.

14. Mihlandız N, Sahin M. Burdur Region Folk Dances. Int J Sci Culture Sport. 2015;3:666-77, https://doi.org/10.14486/ IJSCS331.

15. Scioscia TN, Giffin JR, Fu FH. Knee ligament and meniscal injuries in dancers. Review article. J Dance Med Sci. 2001;5(1):11-5.

16. Liederbach M, Dilgen FE, Rose DJ. Incidence of anterior cruciate ligament injuries among elite ballet and modern dancers: a 5-year prospective study. Am J Sports Med. 2008;36(9):1779-88, https://doi.org/10.1177/0363546 508323644 .

17. Mihata LC, Beutler AI, Boden BP. Comparing the incidence of anterior cruciate ligament injury in collegiate lacrosse, soccer, and basketball players: implications for anterior cruciate ligament mechanism and prevention. Am J Sports Med. 2006;34(6):899-904, https://doi.org/10.1177/0363546505285582.

18. Agel J, Arendt EA, Bershadsky B. Anterior cruciate ligament injury in national collegiate athletic association basketball and soccer: a 13-year review. Am J Sports Med. 2005;33(4):52430, https://doi.org/10.1177/0363546504269937.

19. Ambegaonkar JP, Shultz SJ, Perrin DH, Schmitz RJ, Ackerman TA, Schulz MR. Lower body stiffness and muscle activity differences between female dancers and basketball players during drop jumps. Sports Health. 2011;3(1):89-96, https://doi.org/10.1177/1941738110385998.

20. Hansberger BL, Acocello S, Alater LV, Hart JM, Ambegaonkar JP. Peak lower extremity landing kinematics in dancers and nondancers. J Athl Train. 2018;53(4):379-85, https:// doi.org/10.4085/1062-6050-465-16.

21. Volkerding KE, Ketcham CJ. Biomechanics and proprioceptive differences during drop landings between dancers and non-dancers. Int J Exercise Sci. 2013;6(4):289-99.

22. Kilroy EA, Crabtee OM, Crosby B, Parker A, Barfield WR. The effect of single leg stance on dancer and control group static balance. Int J Exerc Sci. 2016;9(2):110-20.

23. Smith PJ, Gerrie BJ, Varner KE, McCulloch PC, Lintner DM, Harris JD. Incidence and prevalence of musculoskeletal injury in ballet: a systematic review. Orthop J Sports Med. 2015;3(7):2325967115592621, https://doi.org/ $10.1177 / 2325967115592621$.

24. Liederbach M, Kremenic IJ, Orishimo KF, Pappas E, Hagins M. Comparison of landing biomechanics between male and female dancers and athletes, part 2: Influence of fatigue and implications for anterior cruciate ligament injury. Am J Sports Med. 2014;42(5):1089-95, https://doi. org $/ 10.1177 / 0363546514524525$.

25. Orishimo KF, Liederbach M, Kremenic IJ, Hagins M, Pappas E. Comparison of landing biomechanics between male and female dancers and athletes, part 1: Influence of sex on risk of anterior cruciate ligament injury. Am J Sports Med. 2014; 42(5):1082-8, https://doi.org/10.1177/0363546514523928.

26. Ward RE, Fong Yan A, Orishimo KF, Kremenic IJ, Hagins M, Liderbach M, et al. Comparison of lower limb stiffness between male and female dancers and athletes during drop landing. Scand Med Sci Sports. 2019;29(1):71-81, https://doi.org/10.1111/sms.13309.

27. Lee JM, Fu F. Basic science clinical applications. Oper Tech Ortho. 2000;10(3):162-8, https://doi.org/10.1016/S1048-66 66(00)80002-6.

28. Carol CT. Hip and knee injuries in dancers. J Dance Med Sci. 2000;4(1):23-9. 
29. Hewett TE, Lindenfeld TN, Riccobene JV, Noyes FR. The effect of neuromuscular training on the incidence of knee injury in female athletes. A prospective study. Am J Sports Med. 1999;27(6):699-706, https://doi.org/10.1177/036354659 90270060301.

30. Soomro N, Sanders R, Hackett D, Hubka T, Ebrahimi S, Freeston J, et al. The efficacy of injury prevention programs in adolescent team sports: a meta-analysis. Am J Sports Med. 2016;44(9):2415-24,https://doi.org/10.1177/0363546515618372.

31. Aman M, Larsén K, Forssblad M, Näsmark A, Waldén M, Hägglund M. A Nationwide Follow-up Survey on the Effectiveness of an Implemented Neuromuscular Training
Program to Reduce Acute Knee Injuries in Soccer Players. Orthop J Sports Med. 2018;6(12):2325967118813841, https://doi.org/10.1177/2325967118813841.

32. Dargo L, Robinson KJ, Games KE. Prevention of Knee and Anterior Cruciate Ligament Injuries Through the Use of Neuromuscular and Proprioceptive Training: An EvidenceBased Review. J Athl Train. 2017;52(12):1171-2, https://doi. org/10.4085/1062-6050-52.12.21.

33. Acevedo RJ, Rivera-Vega A, Miranda G, Micheo W. Anterior cruciate ligament injury: identification of risk factors and prevention strategies. Curr Sports Med Rep. 2014;13(3):18691, https://doi.org/10.1249/JSR.0000000000000053.

This work is available in Open Access model and licensed under a Creative Commons Attribution-NonCommercial 3.0 Poland License - http://creativecommons.org/ licenses/by-nc/3.0/pl/deed.en. 